\title{
Collarless \\ Coroa metalo-cerâmica com ombro em cerâmica
}

\author{
Ezio Teseo Mainieri* \\ Elken Gomes Rivaldo** \\ Roberto Sperb Seadi***
}

\begin{abstract}
RESUMO
$\mathrm{Na}$ construção de uma coroa, veneer pelo método Stantar, muitas vezes é difícil acomodar a cinta metálica e mantê-la junto ao sulco gengival raso, e quando o paciente apresenta linha do sorriso alta.

O colar de metal tornar-se-á evidente, também em situação de recessão periodontal, envolvendo preparação dentária, terminando na junção cemento-esmalte; um método de construção foi comentado para a resolução de problemas específicos.
\end{abstract}

\section{SUMMARY}

In the construction of a vencer crown in the standar manner, it is sometimes difficult to hide the metal collar and keep from being obtrusive if the gingival cevice is shallow and the patient has a high sipline. The metal color will be notice able also when there is considerable cecession hround periodontally involved teeth if

the preparation is finished at the cemento enamael junction. A method of construction has been

comprented to solve this esthetic problem.

A coroa de jaqueta de porcelana, tem sido a restauraçăo escolhida para se conseguir um bom resultado estético, sempre que os dentes exijam cobertura total da coroa clínica. Quando as restauraçōes dentais de porcelana sofrem forças de compressão ou qualquer tipo de stress, elas oferecem pequena resistência à fratura. Esta indesejável propriedade resulta frequentemente em falhas clínicas que contraindicam o uso das coroas de jaqueta de porcelana.

O desenvolvimento da porcelana dental reforçada com óxido de alumina (AL2O3) possibilitou aumentar a resistência à tensăo e ao stress nas coroas de jaqueta de porcelana. O aumento na força da coroa de jaqueta de porcelana fabricada com estes materiais năo foi no entanto, totalmente estabelecida, além disto, a alumina diminui a translucidez da porcelana.

As restaurações metalo-cerâmicas foram desenvolvidas como uma outra maneira de reduzir o risco da fratura da porcelana. Este tipo de restauraçăo proporciona uma sub-estrutura de metal para reforçar a porcelana. O procedimento recomendado para a preparação do casquete para receber a porcelana, inclui a formaçăo de um fino colar cervical de metal. O colar metálico proporciona um efeito de suporte, o que reforça $o$ casquete e habilita este, a resistir a deformação durante os ciclos de cocção envolvidos na fabricação das restauraçōes metalo-cerâmicas.

Infelizmente, o colar metálico produz um problema estético de uma linha preta ou de um escurecimento do tecido gengival. Ele também pode se tornar visível se ocorrer retração gengival. Também a porcelana próxima ao colar é menos translúcida em funçăo do opaco estar próximo da superfície externa.

Para ajudar a superar estes pro- blemas, muitos técnicos de laboratório, reduziram o colar metálico a uma fina linha menos visível. Esta fina porção metálica está sujeita a distorções durante a cocção da porcelana. Esforços para mascarar o colar metálico, cobrindo-o com porcelana também são comuns, mas tal fato resulta normalmente em sobrecontorno junto ao tecido gengival. Este sobrecontorno promoverá um possível acúmulo de placa na junção dentogengival culminando com a inflamação gengival.

Para situações que referem às vantagens estruturais das coroas metalo-cerâmicas e as qualidades estéti-

\footnotetext{
* Prof. Coordenador do Curso de Pós-Graduaçāo em Prótese Dental e das Disciplinas de Prótese Parcial I e II da FO/UFRGS - Porto Alegre

** Aluna do Curso de Pós-Graduação em Prótese Dental da FO/UFRGS - Porto Alegre *** Aluno interno das Disciplinas de Prótese Parcial I e II da FO/UFRGS - Porto Alegre
}

R. Fac. Odontol.

Porto Alegre
V. 32

N. 2 
cas da coroa de jaqueta de porcelana, especialmente na porção cervical, outra alternativa está disponivel. A fabricaçăo de uma restauração metalo-cerâmica sem o colar cervical vestibular de metal, combina as qualidades desejáveis, tanto da coroa metalo-cerâmica quanto das coroas de jaqueta pura. Esta restauração é chamada de collarless.

\section{INDICAÇÕES E CONTRA- INDICAÇOOES DA COROA COLLARLESS}

As restaurações M.C. collarless são particularmente indicadas para pacientes com fino e tênue contorno gengival. A linha de terminação pode ser colocada supra-gengival, sem mostrar o colar metálico. Pacientes com linha do sorriso alta ou dentes finos, acham este tipo de restauraçăo esteticamente superior, porque não existe metal na porção cervical e a espessura de porcelana é maior. Dentes que apresentam retrataçăo gengival ou que estejam alinhados de maneira a não permitir que a preparação seja estendida sub-gengivalmente, podem ser restaurados com vantagem nesta técnica. Em situações clínicas, onde há retração gengival ou em pacientes com proeminência dos caninos superiores, o tratamento pode ser tranquilamente executados sem medo de que o colar metálico fique exposto.

A remoção do colar metálico cervical vestibular, resulta em um casquete menos rígido e contraindica o seu uso como retentor (sujeito à força de torção), em casos onde a linha de terminaçăo vestibular é irregular, tornando difícil a fabricaçăo de uma CMC collarless, que se adapte perfeitamente em função da dificuldade de adaptaçăo da porcelana, e em pacientes com oclusăo topo a topo.

\section{PREPARO PARA COROA COLLARLESS}

Quando um dente está sendo preparado para receber uma coroa collarless, a superfície vestibular deve ser reduzida em 2 planos: um quase paralelo ao plano de inserção e outro paralelo aos dois terços incisais da superfície vestibular do dente. A redução somente no plano paralelo de inserçăo pode resultar em espaço insuficiente para a porcelana no terço incisal, o que é um erro comum. A redução em um plano cria espaço adequado para a restauração no ombro e nas áreas incisais, ficando perigosamente próximo da polpa na área média da vestibular e também pode produzir um preparo muito cônico.

São feitos sulcos de orientação na face vestibular dois na porção incisal e dois na porção gengival. $\mathrm{Na}$ borda incisal são feitos sulcos com $2,0 \mathrm{~mm}$ de profundidade. A broca deve ficar paralela ao ângulo da borda incisal, procedendo-se então, a redução incisal, com uma broca diamantada cônica de ponta chata. A redução vestibular é realizada, mantendo-se os dois planos, e estendendo-se bem nas superfícies proximais. A redução da metade gengival é feita com a broca diamantada cônica de ponta chata, formando o ombro vestíbulo-gengival.

A reduçăo lingual ou palatina é feita com uma roda diamantada pequena, tomando cuidado para não estender muito gengivalmente sobre o ângulo, pois a parede lingual vertical pode ficar muito diminuida. A redução, axial-lingual é feita usando-se uma broca diamantada torpedo e broca de acabamento de carbide. A parede axial-lingual deve ser paralela ao terço cervical da superfície vestibular.

Redefinir e alisar o ombro vestibular que forma um ângulo quase reto com a superfície externa da estrutura do dente. Para garantir um ombro uniforme, é usada a broca 957 e uma machadinha de esmalte de $1,0 \mathrm{~mm}$ de largura, planificando a superfície do ombro e verificando a sua largura. O acabamento do chanfro lingual é feito com a broca carbide. Alisar toda a superfície vestibular com uma broca carbide 171 e arredondar as Aletas proximais (uniăo do ombro vestibular com o chanfro lingual) os ângu- los agudos na borda incisal também devem ser arredondados.

\section{CARACTERÍSTICAS DE UM PREPARO PARA COROA COLLARLESS}

- ombro vestibular (adaptação da porcelana).

- chanfro lingual (integridade marginal).

- redução axial (retenção e resistência, durabilidade estrutural).

- redução côncava do ângulo (durabilidade estrutural).

- parede lingual vertical (retenção e resistência).

- arredondamento dos ângulos (durabilidade estrutural).

\section{TÉCNICAS PARA A CONFECÇÃO DA COROA COLLARLESS}

- a técnica da lâmina de platina.

- modelo refratário para cocção direta da porcelana.

- remoção direta da porcelana do ombro.

A técnica da lâmina de platina apresenta o incoveniente de após a remoção da lâmina, a coroa não adaptar totalmente sobre a margem, visto que, a lâmina age como um espaçador, como na técnica da jaqueta pura, por esta razão haverá sempre uma fenda inicial de no mínimo $0,025 \mathrm{~mm}$, ou seja, a espessura da própria lâmina.

Sozio (1977) descreveu uma técnica para cozer a porcelana diretamente sobre um modelo refratário, no qual, um agente condicionador de metal é aplicado ao ombro vestibular para ajudar no umedecimento do metal pela porcelana. Quando cozido, o agente condicionador que contém ouro coloidal adere ao modelo refratário, formando uma fina camada sobre a área do ombro. 0 agente condicionador tem aproximadamente 10 a 20 micras de espessura. Quando a camada do opaco é cozida sobre este agente, uma boa adesão é obtida e a coroa pode ser adaptada sobre a superfície para proporcionar o completo assentamento da porcelana. 
Depois que o ombro de porcelana foi formado, o modelo refratário pode ser deslocado do conjunto pela imersão em água, e finalmente limpo pelo ultra-som.

O casquete completado com a cerâmica de ombro pode então ser transferido para o modelo principal e aborda terminada pelos procedimentos normais.

Outra técnica descrita por toogood e Archibald (1978), baseia-se na remoção direta da porcelana da margem. A coroa é confeccionada e após a primeira cocção uma fenda marginal de $0,5 \mathrm{~mm}$ é confeccionada com uma ponta de diamante, exatamente sobre o ombro vestibular. $\mathrm{Na}$ segunda cocção, qualquer imperfeição será corrigida, mas a fenda vestibular de $0,5 \mathrm{~mm}$ é mantida.

O ombro do troquel é lubrificado com um separador e a porcelana aplicada sob o troquel, removido o casquete metálico. Isto é importante, uma vez que a fenda é muito pequena e é impossível vibrar uma pequena porção de porcelana pelo espaço, com a coroa acentada sob o troquel (Fig 3). Assim, quando a coroa é acentada de novo sob o troquel ela é facilmente vibrada para a posição e a margem finalmente selada com mais porcelana (Fig. 1).

A coroa pode agora ser deslocada do troquel e a margem cozida a 650 a $910^{\circ} \mathrm{C}$ sem vácuo.

A margem é refinada, acabada com um disco. $O$ glase é dado por 3 minutos a $900^{\circ} \mathrm{C}$ (Figs. 2, 3, 4).

A técnica da remoçăo direta de porcelana, mostra-se rápida e simples. No entanto, ela sofre uma desvantagem, qualquer cocção posterior pode causar distorção marginal, devido a grande piroplasticidade da porcelana.

Por esta razăo, foi desenvolvida uma mistura especial de porcelana para a obtenção de um assentamento direto da porcelana, sob a coroa MC. A fim de reduzir a piroplasticidade da porcelana, durante a cocção, foi acrescentada alumina à matriz de vidro. Embora a expansão térmica dos cristais de alumina e a porcelana não se combinem, a quantidade de material usada é tão pequena que os efeitos da diferença de expansão térmica e a resultante tensão da porcelana nāo significam um problema na clínica.

Essa mistura especial de alumina com o corpo da porcelana pode ser feita como segue: $1 / 3$ da porcelana de corpo vitadur e 2/3 de opaco regular VMK 68.

A mistura pode ser cozida a $940^{\circ} \mathrm{C}$ e a porcelana na opaca VMK 68 , fuirá ao redor e umedecerá o corpo dos cristais de alumina, os quais agiram como um reforço.

Para porcelana gengival com alumina permanecerá estável e manter-se-á assentada sobre a margem vestibular durante a construção da coroa MC. Essa técnica usando porcelana gengival - opaco + alumina foi idealizada por Hubbard (1977).

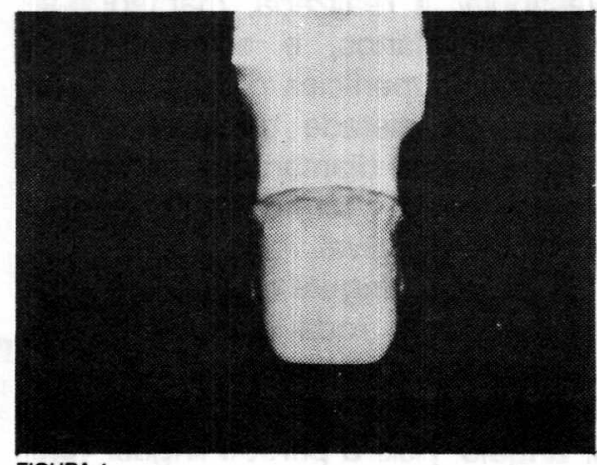

FIGURA 1

\section{REFERÊNCIAS BIBLIOGRÁFICAS}

01. BRECKER, S.C. - Porcelain baked to gold A new medium in prosthodontics. $J$. prosthet. Dent. 6:801-810, 1956.

02. BRASCKEIT, Jacobi, Shillingburg - Fundamentos dos preparos dentários, para restauraçōes metálicas e de porcelana. Quintessence Editora Ltda., 1988.

03. EISSMANN, H.; RODKE, R. and BOBLE, W. - Physiologic design criteria for fixed dental restorations. Dent. Clin. North Am. 15:3, 543-567, 1971.

04. GOODACRE, J.; Charles; ROEKEL, V.B. Ned, Dukems, W. Roland and ullmann, Brian - The collarless metal-ceramica crown. J. Prosthet. Dent. 6:6515-622, 1977.

05. EISSMANN, H.; RODKE, R. and BOBLE, W. - Physiologic design criteria for fixed dental restorations. Dent. Clin.

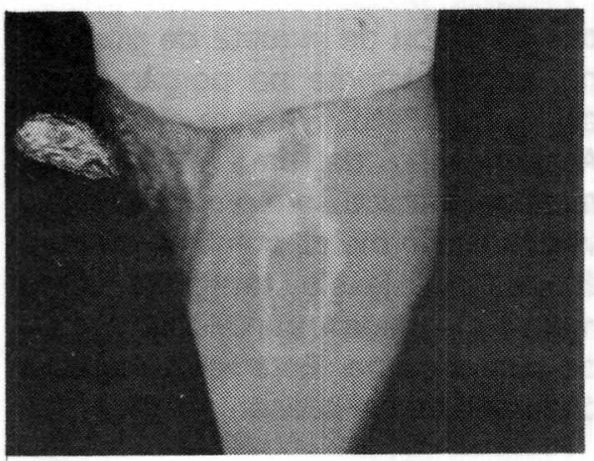

FIGURA 2

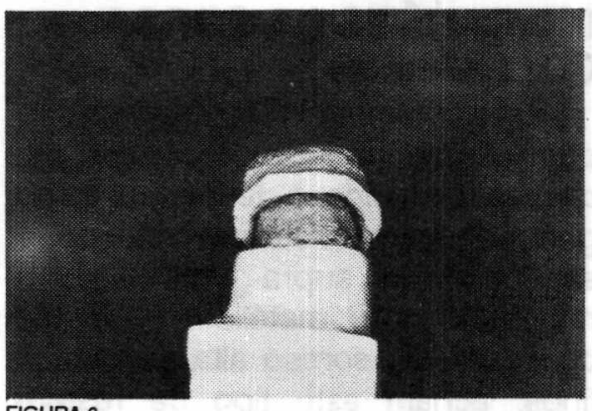

FIGURA 3

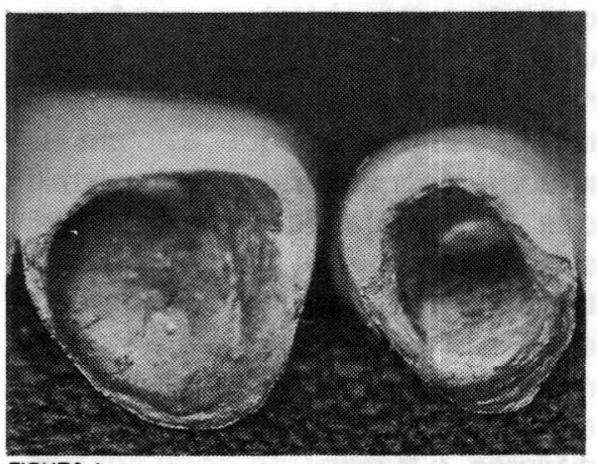

FIGURA 4
06. IOUDNIS, R.; WEAVER, J. and SAPKOS, S. - Facial and lingual contours of artificial complete crown restorations and their effects on the periodontium. J. prosthet. Dent. 29:61-66, 1973.

07. RILEY, E.; SOZIO, R.; Casthely, F. - Precision porcelain Jacket croket crown technique. J. prosthet. Dent. 34:346-351, 1975.

08. SHILLINGBERG, H.; HOBO, S. and tisser, D. - Preparation design and margin distortionin porcelain fused to metal restorations. J. prosthet. Dent. 20:276-284, 1973.

09. SOZIO, B.R. - The marginal aspect of the ceramo-metal restoration the collarless ceramo-metal restoration. The dental clinics of north america. Vol. 21, $\mathrm{N}^{\circ} 4$, 787-802, 1977.

10. WHERLER, R.C. - Complete crown form and periodontium. J. prosthet. Dent. 11:722-734, 1961. 